\title{
A Study To Evaluate The Shape And Size of Sella Turcica And Its Correlation with The Type of Malocclusion on Lateral Cephalometric Radiographs
}

\author{
${ }^{1}$ Mukta B. Motwani, ${ }^{2}$ Rohit Biranjan, ${ }^{3}$ Apeksha Dhole, \\ ${ }^{4}$ Anuraag B. Choudhary, ${ }^{5}$ Apurva Mohite \\ ${ }^{I}$ Professor \& Head, Department Of Oral Medicine \& Radiology, VSPM's Dental College \& Research Centre, \\ Nagpur, India \\ ${ }^{2}$ Post Graduate Student, Department Of Oral Medicine \& Radiology, VSPM's Dental College \& \\ Research Centre, Nagpur, India. \\ ${ }^{3}$ Professor, Department Of Oral Medicine \& Radiology, VSPM's Dental College \& \\ Research Centre, Nagpur, India \\ ${ }^{4}$ Associate Professor, Department Of Oral Medicine \& Radiology, VSPM's Dental College \& \\ Research Centre, Nagpur, India \\ ${ }^{5}$ Senior Lecturer, Department Of Oral Medicine \& Radiology, VSPM's Dental College \& Research Centre, \\ Nagpur, India
}

\begin{abstract}
Introduction: Lateral cephalograms display numerous cranial, facial and oral anatomic structures along with sella turcica which is considered vital for many radiographic analyses. It is demarcated by dense thin white line and is used to measure the position of maxilla \& mandible in relation to the cranial base and to themselves. Various studies have found an association between morphological variations of sella to malocclusion and also gender differences have been noted. This retrospective study was carried out to evaluate these morphological variations of sella turcica and its relation to type of malocclusion.

Aim: To determine dimensions and morphological variations of sella turcica in different age groups \& correlation between sella and type of malocclusion.

Materials And Methods: 200 lateral cephalometric images of the patients more than age group of 8 years and less than 25 years were selected. The morphological variations, linear measurements of sella turcica and the skeletal type classification, based on ANB angle was determined. Length, depth, antero-posterior diameter (linear dimentions) were measured and correlated with the type of malocclusion.

Results: Out of the total sample studied, it was found that, when linear measurements were assessed, there was statistically significant difference found between the length and antero-posterior diameter of sella turcica. When skeletal type malocclusion was assessed, there was no significant correlation found between sella morphology, linear dimensions and the different types of malocclusion.

Conclusion: The study showed significant correlation between the length and the anteroposterior diameter with the advancing age which signifies that growth of the individual can be assessed based on the size of sella turcica at different age periods.
\end{abstract}

Keywords: Lateral cephalogram, Sella turcica, Sella dimensions and morphology, Type of malocclusion.

\section{Introduction}

A lateral cephalometric radiograph displays numerous cranial, facial and oral anatomic structures imaged from lateral aspect and which aids in diagnosis, treatment planning and predicting the treatment outcome. It is used to assess the craniofacial morphology, allowing to distinguish between dentoalveolar malocclusions and skeletal discrepancies. Apart from facial structures, fossa cranii media, including the sella turcica, are visible on these radiographs. ${ }^{[1,2]}$ Proper analysis of the craniofacial skeleton on lateral cephalogram depends upon accurate identification and location of defined anatomical and constructed landmarks. Sella turcica is considered important landmark for many of radiographic analysis of the neurocranial and craniofacial complex. Sella turcica is a saddleshaped concavity in the body of the sphenoid bone situated in the middle cranial fossa of the skull which is variable in size and shape. ${ }^{[2]}$ It can be deep or shallow in both children and adults. ${ }^{[2]}$ Sella turcica gets its name from Turkish language because of its similarity to the Turkish saddle. The depression in saddle is noted as pituitary fossa or hypophyseal fossa, ${ }^{[3]}$ as the pituitary gland is situated here. In lateral cephalometric radiographs, the sella turcica is usually demarcated by a dense thin white line and such a landmark is used to measure the positions of maxilla and the position of mandible in relation to the cranium base and to themselves. ${ }^{[5]}$ Sella turcica on lateral cephalometric radiograph can be observed clearly and consecutively traced during cephalometric analysis. ${ }^{[4]}$ 
According to the study conducted by Kucica et al, it was found that children with abnormal structure of sella, especially with sella turcica bridges are characterized by significantly higher incisor inclination angles and a more distal position of the alveolar part of the mandible. ${ }^{[1]}$ This indirectly indicates a more distal position of the maxillary and mandibular basal bones than in unaffected individuals and also confirms general aetiology of malocclusion. Malocclusion, a distortion of the normal growth and development' can be skeletal or dental in origin. Various angular and linear measurements have been incorporated in various cephalometric analyses for characterization of patient's craniofacial skeleton and also to help clinicians in diagnosing the amount of skeletal and dental discrepancies, contributing towards the presenting malocclusions. ${ }^{[6,]}$ Since there is an increasing interest in the study of human craniofacial dysmorphology, it is essential to estabilish the cephalometric norms for the normal growth and development of sella turcica and should be carried out during cephalometric analysis.

Thus, the aim of this study was to determine the average dimensions and morphological variations of the sella turcica in different age groups and its correlation with the type of malocclusion on lateral cephalometric radiographs in the study population visiting VSPM dental college and research centre, Nagpur (Maharashtra). The objective of the study was, to evaluate correlation between linear dimensions and morphology of the sella turcica with gender and to evaluate correlation between linear dimensions and morphology of the sella turcica in subjects with different skeletal pattern.

\section{Method}

After obtaining permission from the ethical committee, 200 lateral cephalograms in the age group of 8-25 years, which had good quality, in which all cephalometric structutres were clearly visible, which showed good reproduction of the sella turcica were retrieved from the existing 2 years record of the patients in the Department of Oral Medicine and Radiology, V.S.P.M Dental college, Nagpur. These cephalograms were grouped into four categories based on age i.e < 10 years, 10-15 years, 16-20 years, 21-25 years. All cephalograms were analysed as monitor-displayed images using Kodak dental software program. Radiographs with congenital defects in the craniofacial region like clefts and other malformations and the radiographs of subjects with less than 8 years of age and more than 25 years were not selected.

\section{1) Distribution into skeletal classes}

Classification of skeletal type type into Class I, Class II, or Class III was be based on the ANB angle (SNA and SNB) from Stiener Analysis. The ANB angle indicates the magnitude of the skeletal jaw discrepancy, regardless of which jaw is affected.

Skeletal base Class were categorised as follows:

1.1 Angle from 0-4 degrees - Class 1

1.2 Angle more than 4 degrees - Class II, and

1.3 Angle less than 0 degrees Class III.

\section{2) Size of sella turcica}

Three linear measurements of the sella turcica i.e. length, antero-posterior diameter and depth in mid-sagittal plane were obtained in accordance to Silverman and Kisling methods. ${ }^{\mathbf{8 9}}$

2.1. The length of sella turcica was measured as the linear distance from the superior most point on the tuberculum sella to the tip of the dorsum sella.

2.2 The depth was measured as a line perpendicular from the line joining tuberculum sella and dorsum sella to the inferior most point on the floor.

2.3 The anteroposterior diameter of sella turcica was measured from the superior most point on tuberculum sella to the furthest point on the posteroinferior aspect of the hypophyseal fossa.(fig 1)

\section{3) Shape And Morphological Appearance Of Sella Turcica}

Shape and morphological appearance of sella turcica was assessed according to the method described by Axelsson et al. ${ }^{[8]}$ According to Axelsson et al., the five morphological variations are oblique anterior wall, bridging of sella turcica, double contour of the floor, irregular surface (notch like depression) in the posterior aspect of the dorsum sella, and pyramid shape of dorsal sellae. ${ }^{[8]}$

\section{Results And Statistical Analysis}

Data were analysed using the Statistical software SPSS version 18. P-value was estimated using one way analysis of variance for distribution of subjects and comparison of measurement of sella turcica according to age intervals. Pair wise comparison of mean length of sella turcica and mean A-P diameter of sella turcica according to age age intervals was also observed. A Student's t -test was used to calculate the mean differences in sella turcica linear dimensions between males and females (significance level<0.05). Distribution of subjects on the basis age and as per types of morphology was observed. Distribution of subjects on the basis gender, types of malocclusion and 
types of morphology was seen. To study the relationship between skeletal type and sella turcica size, t-test for independent samples was performed. Distribution of subjects on the basis of gender as per groups of morphology was also analysed. Distribution of subjects on the basis of types of malocclusion as per groups of morphology was even observed.

\section{1) Size of sella turcica}

The linear measurements of sella turcica in various age groups are presented in table 1. Length of sella turcica consistently went on increasing as the age advances, which was not true with the height/depth and the diameter (decreased in the last age group) Table 1 . When level of significance was carried out, it was observed that $\mathrm{P}$ value was significant with only the length and not with the other two linear dimension (depth/height and the diameter). The average length, depth and diameter of the sella turcica is shown for male and female in table 2 . The mean length of sella turcica in males and females varied by only $0.978 \mathrm{~mm}$ being $9.104 \mathrm{~mm}$ in males and $8.126 \mathrm{~mm}$ in females, suggesting men have wider sella as compared to females Table 2. Similarly when comparison of the mean diameter between both genders was carried out, it was found that, the mean value varied by only $0.179 \mathrm{~mm}$ being $10.185 \mathrm{~mm}$ in females and $10.006 \mathrm{~mm}$ in males. On comparison of mean depth between the male and female the values also varied by $0.29 \mathrm{~mm}$ i.e. in females the depth/height was more as compared to males. Finally, on comparing the $\mathrm{p}$ value in all three linear dimension between genders, it was found that only the length parameter showed significant difference and no difference was observed in depth and diameter of sella turcica. (table 2)

\section{2) Morphology/ Shape of sella turcica}

Normal sella morphology was predominant in all the age groups whereas the next common was the sella bridge.(table 3). On seeing the morphology of sella turcica in each the skeletal types, the results showed that In skeletal class I patients $48.10 \%$ (38/79) of patient had normal sella and 46.15\% (18/39) of the patients had sella bridge (Table 4). In skeletal class II patients $51.89 \%$ (41/79) of the patients had a normal sella and 53.84\% (21/39) of the patients has sella bridge. Sella bridge was more common in class II patients (table 4). The present study did not find images of class III or skeletal class III patients to analyse the data, as the images were retreived randomly and hence the data was confined to class I and class II subjects' images only.

\section{3) Skeletal pattern and linear dimensions of sella turcica}

In order to determine if the patients with different skeletal pattern presented with different linear dimensions irrespective of age and gender, a student t-test was performed. No significant difference was found between the different linear dimensions and skeletal pattern. The mean difference between skeletal pattern with different linear dimension are shown in table 5.

\section{Discussion}

It is known that at the age of 8 years, the mean diameter of the sella turcica is $10 \mathrm{~mm}$ and at the age of 16 years, it is $11 \mathrm{~mm}$. It is strictly dependent on hypophysal morphology, thus, size alterations may be symptoms of glandular pathology and should be subjected to further diagnosis. ${ }^{2}$ Morphological aberrations of the sella turcica described in the literature are bridge, oblique anterior wall, double contour of the floor, irregularity (notching) in the posterior part of the dorsum sella and pyramidal shape of the dorsum sellae. ${ }^{8,9,14,15,16,17}$ However, it should be remembered that the two-dimensional representation of an abnormality system does not really provide complete information about its three-dimensional structure. An infinitive number of three-dimensional sizes and shapes can yield an identical two-dimensional radiographic image, which constitutes a well proven mathematical fact inherent to two-dimensional radiography.

\section{1) Shape/Morphology of Sella turcica}

In the previous years Gorden and Bell (1922) classified sella into shapes (circular, oval or flat/saucer shaped but they concluded that not all the cases could easily be put into such a broad three way classification. ${ }^{[15]}$ Then in 1950 David and Epstein used the term J shaped sella while omega shaped sella was given by Pournier and Denizet in 1965. ${ }^{[18]}$ However in 1969 Kier termed these definitions radiographical myths, advising that both should be disregarded since they were used to characterize abnormal pathology as well as normal developmental patterns. ${ }^{[18]}$

In a recent study by Axelsson et al in 2004, shape of the sella turcica was divided into six main types; normal sella turcica, oblique anterior wall, double - contoured sella, sella turcica bridge, irregularity (notching) in the posterior part of the sella and pyramidal shape of the dorsum sellae. ${ }^{[8]}$ Alkofide in 2007 did a similar study using the same 6 main types of sella shapes as Axelsson et al has used, and, he reported the similar findings, that, the normal variation of sella shape was almost in $67 \%(2 / 3 \mathrm{rd})$ of the subjects. ${ }^{[\mathbf{9}, \mathbf{8}]}$ In our study the normal variation was observed in $39.5 \%$ of the subjects whereas $60.5 \%$ had different variations. These values are not in accordance to study by Axelsson and Alkofide. ${ }^{[8,9]}$ 
The finding of an irregular notching of the dorsum sella was very less in the current study being $3 \%$ whereas in Axelsson study it was $11 \%$ and Sathyanarayana et al it was $15 \% .{ }^{[8,13]}$ Similarly the pyramidal shape of the dorsum sella was more frequent in the current study than the former. ${ }^{[3,8,13]}$ The difference in the values between the two studies can be attributed to the ethnic difference between the two samples.

The double contour frequency was also found in less number in the present study (only 1.5\%) than the former study. ${ }^{[3,8,13]}$ The oblique anterior wall has been documented in normal (Axelsson), as well as in children suffering from lumbosacral myeomeningocele and seckel syndrome. ${ }^{[19]}$ The current study showed only $5.5 \%$ of subjects with an oblique anterior wall which is not in agreement to Axelsson et al(26\%) and Nagraj et al(29\%) but in accordance to Kucia A et al, Shah AM et al(4\%),Alkofide $(9.4 \%)$ and Satyanarayan et al $(5 \%)$. The another description regarding sella turcica was " sella bridge " which was given recently by Camp JD. ${ }^{16}$ The frequency of sella turcica bridge in the present study has been presented in table 4 . In previous studies on healthy subjects, the occurrence of sella bridging ranged from $4.6 \%$ to $11.1 \% .^{[5,8]}$ In present study sella turcica bridge was found to be $19.5 \%$ which is in accordance to Axelson et al who also found that the presence of sella turcica bridge in normal individual is not uncommon and is seen in $5.5 \%-22 \%$ of the subjects ${ }^{[8]}$. Present study is not in accordance with the study by Shah et al and Alkofide. ${ }^{[\mathbf{1}, 9]}$ It raisies an interesting point for future studies as to whether the bridging variation of sella type even exists in normal individuals or not.

The higher occurrence of sella turcica bridge in females in the present study supports earlier findings by Axelsson et al. ${ }^{[8]}$ Apart from bridging, the present study also supports a higher prevalence of sella turcica bridges in patients with malocclusion than in healthy individuals, and the same was also previously reported by Jones et al and Meyer-Marcotty et al. ${ }^{[10,5]}$ Moreover, a higher prevalence of sella turcica bridging and abnormal sella turcica dimensions has been found in subjects who had combined surgical-orthodontic treatment than in subjects who were treated by orthodontic means only. ${ }^{[10]}$ Similarly, a higher frequency of sella turcica bridge has been found in patients with severe craniofacial deviations too. ${ }^{[11]}$ Marsan G and Oztas E, Meyer-Marcotty et al and Sathyanarayana et al reported that sella turcica bridges are more frequent in Class III patients. ${ }^{[12,5,13]}$ These findings were not in accordance to the present study as the current study found more sella bridges in class II cases.

These finding have a clinical significance, since the presence of a skeletal component of a malocclusion makes the treatment always more complex than a malocclusion of dentoalveolar origin only.

\section{2) Size of sella turcica}

Similar to the morphological studies numerous studies have been done on the size of sella turcica, however the methods differ widely. Camp reported value of the width (termed as length in our study) being $10.6 \mathrm{~mm}$, Shah AM et al found $11.3 \mathrm{~mm}$, Quakinine and Hardy found $12 \mathrm{~mm}$, Asad and Hamid found 14.9 and Alkofide who observed length to be $10.3 \mathrm{~mm} .^{[\mathbf{1 6 , 1 , 2 0 , 2 1 , 9 ]}}$ In present study the length ranged from a (minimum)5.918mm$11.614 \mathrm{~mm}$ (maximum) with a mean of $8.4 \mathrm{~mm}$. There is slight amount of differences between the values founds in present study and various other studies but these differences are due to different methods of measurements used and the ethnicity. Average height(vertical diameter) found by Quakinine and Hardy was 8mm, in Camp's study, they found it to be $8.1 \mathrm{~mm}$, Nagraj $\mathrm{T}$ et al showed the value as $8 \mathrm{~mm}$, Asad and Hamid found it as $6.4 \mathrm{~mm}$, Alkofide observed the height to be $10.3 \mathrm{~mm}$ and Shah's finding was $9.9 \mathrm{~mm} \cdot{ }^{[\mathbf{2 0 , 1 6 , 3 , 2 1 , 9 , 2 0 ]}}$ Height in the present study varied from (minimum) $4.393 \mathrm{~mm}-8.25$ (maximum) with a mean of $6.06 \mathrm{~mm}$, which is less than the values found in the previous studies except for the study by Quakinine and Hardy, where the value of height was similar. ${ }^{[20]}$ Quakinine and Hardy added that when measuring the size of sella turcica the height of the gland was usually $2 \mathrm{~mm}$ shorter than the depth of sella turcica.(i.e. the gland does not fill the whole volume of the sella turcica) ${ }^{\text {[20] }}$

Antero-posterior diameter with the values ranging from $7.532 \mathrm{~mm}-12.626 \mathrm{~mm}$, mean of $9.94 \mathrm{~mm}$ also varied in this study. Quakinine and Hardy found antero-posterior diameter to be $8 \mathrm{~mm}$, Nagraj et al found it to be $12 \mathrm{~mm}$ Alkofide found it to be $14 \mathrm{~mm}$ and Shah also found it to be $14 \mathrm{~mm} \cdot{ }^{[20,3,9,1]}$ In determining if gender played a difference in terms of sella size, present study found a significance difference between males and females in terms of length. This was not in agreement with the study reported by Israel, Axelssons et al, Nagraj et al, Alkofide who concluded that the sella turcica size in young adults males and females were almost the same. ${ }^{[2,8,3,9]}$ The finding that the increase in size of the sella turcica with age in males was similar to the study carried out by Israel, Silverman, Shah AM, Nagraj et al, Axelsson et al and Sathyanarayan et al and Alkofide. ${ }^{[22,23,1,3,8,13,9]}$ The reason for this is the pubertal growth spurt which occurs 2 years earlier, as reported by Hass. Hass also reported in 1954 that when compared the mean size of sella turcica in terms of sella turcica area in millimetres square till the age of 17 , the area of sella turcica in males was more however after age of 17 years, the sella turcica area in females is slightly larger compared to males. When age criteria was concerned present study was in accordance to the study by Axelsson et al, Nagraj et al but only in terms of diameter which went on increasing with the age ${ }^{[8,3]}$ The current study was not in accordance to their $^{[8,3]}$ study in terms of depth/height of sella. In terms of length and diameter, the current study and the study by Alkofide was in accordance to eachother. ${ }^{[9]}$

\section{3) Relation of Sella turcica with Malocclusion}


The literature shows that there have been very few studies comparing the skeletal type of malocclusion with the sella turcica size to evaluate whether there exists any relation between the two. Present study did not find any significant correlation between the size of sella and the type of malocclusion. This is in agreement with the study conducted by Preston, Shah AM et al and Sthyanarayan et al but not in accordance to Alkofide who found correlation in Class III with the one of the three linear measurement, the diameter. ${ }^{[25,1,13,9]}$

Thus, by seeing the above discussion of this literature, each orthodontist and general dental practioner should be familiar with the different shapes and sizes of sella turcica, to help in differentiation and distinguishing pathology from the normal development patterns.

\section{V . Figures and Tables}

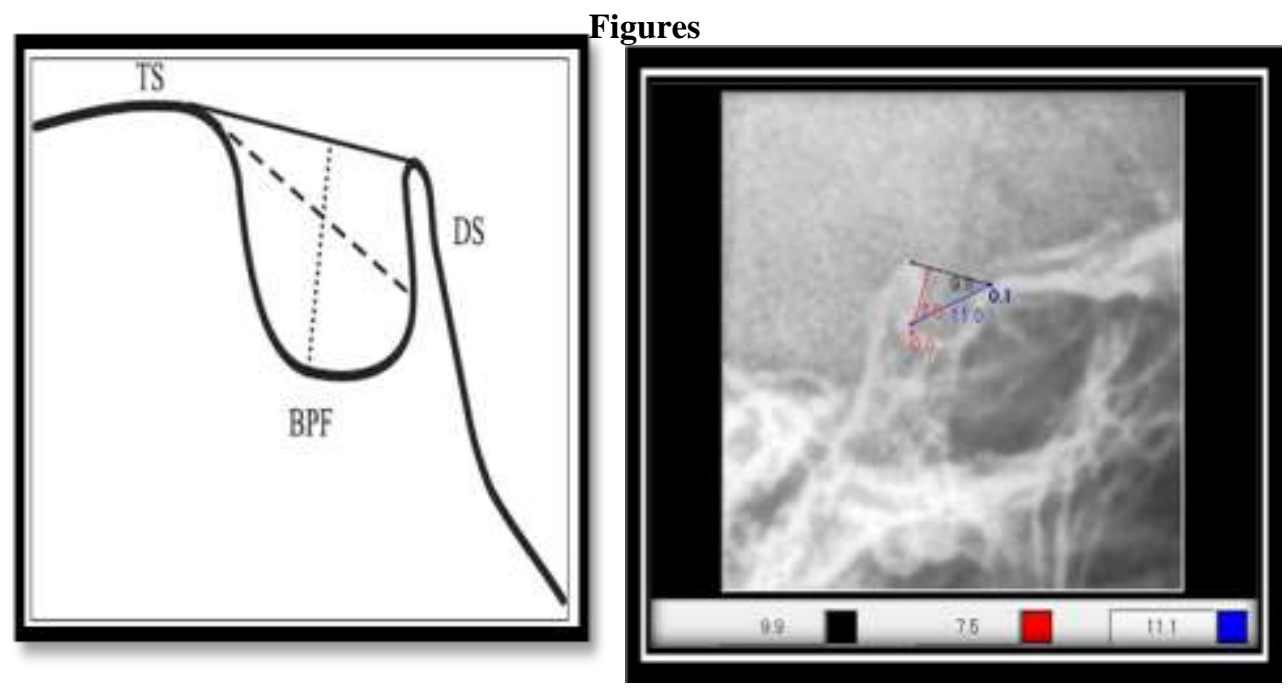

Fig 1

Black line- length of the sella

Dashed line - antero-posterior diameter of sella

Dotted line- depth of sella

TS - Tuberculum sella

DS - Dorsum sella

$\mathrm{BPF}$ - Base of the pituitary fossa

TABLES:

Table 1: Distributionof Subjects and Comparisonof Measurement of Sella Turcica according to age intervals (N=200)

\begin{tabular}{|l|c|c|c|c|}
\hline Age (in years) & No. $(\%)$ & Length $($ Mean \pm SD) & Height $($ Mean \pm SD) & A-P Diameter (Mean \pm SD) \\
\hline$\leq 10$ & $28(14)$ & $7.514 \pm 1.596$ & $5.521 \pm 1.128$ & $8.996 \pm 1.464$ \\
\hline $11-15$ & $85(42.5)$ & $8.258 \pm 2.255$ & $6.241 \pm 1.487$ & $10.246 \pm 1.574$ \\
\hline $16-20$ & $65(32.5)$ & $8.871 \pm 2.761$ & $6.474 \pm 1.614$ & $10.465 \pm 2.161$ \\
\hline $21-25$ & $22(11)$ & $9.177 \pm 2.437$ & $6.041 \pm 1.771$ & $10.091 \pm 1.587$ \\
\hline & $200(100)$ & $\mathbf{0 . 0 1 0 4} *$ & $0.2120^{*}$ & $\mathbf{0 . 0 0 3} *$ \\
\hline
\end{tabular}

$* P$-value estimated usingone way analysis of variance; $P$-value in bold indicate statistical significance

Table 2: Distribution of subjects and comparisonof measurement of Sella turcica as per gender ( $\mathrm{n}=200)$

\begin{tabular}{|l|c|c|c|c|}
\hline Gender & No. $(\%)$ & Length (Mean \pm SD) & Height (Mean \pm SD) & A-P Diameter (Mean \pm SD) \\
\hline Male & $67(33.5)$ & $9.104 \pm 2.583$ & $6.001 \pm 1.533$ & $10.006 \pm 2.092$ \\
\hline Female & $133(66.5)$ & $8.126 \pm 2.263$ & $6.291 \pm 1.538$ & $10.185 \pm 1.679$ \\
\hline & $200(100)$ & $\mathbf{0 . 0 0 9 6 *}$ & $0.2102^{*}$ & $0.5440^{*}$ \\
\hline
\end{tabular}

significance

* $P$-value estimated using $t$-test for independent samples; $P$-value in bold indicate statistical 
Table 3: Distribution of subjects on the basis age and as per types of morphology $(\mathrm{n}=200)$

\begin{tabular}{|l|c|c|c|c|}
\hline \multirow{2}{*}{ Morphology } & \multicolumn{3}{|c|}{ Age (in years) [No. (\%)] } \\
\cline { 2 - 5 } & $\leq 10$ & $11-15$ & $16-20$ & $21-25$ \\
\hline Normal sellaturcica & $11(39.29)$ & $32(37.65)$ & $29(44.62)$ & $7(31.82)$ \\
\hline Bridge & 0 & $18(21.18)$ & $16(24.62)$ & $5(22.73)$ \\
\hline Hypertrophic posterior clinoid process & $1(3.57)$ & $4(4.71)$ & $2(3.08)$ & $1(4.55)$ \\
\hline Hypotrophic posterior clinoid process. & 0 & $3(3.53)$ & $1(1.54)$ & $1(4.55)$ \\
\hline $\begin{array}{l}\text { Irregularity (notching) in the posterior part of the } \\
\text { sellaturcica. }\end{array}$ & 0 & $2(2.35)$ & $1(1.54)$ & $3(13.64)$ \\
\hline Pyramidal shape of the dorsum sellae & $8(28.57)$ & $10(11.76)$ & $5(7.69)$ & 0 \\
\hline Double contour of the floor. & 0 & 0 & $2(3.08)$ & $1(4.55)$ \\
\hline Oblique anterior wall & $2(7.14)$ & $7(8.24)$ & $1(1.54)$ & $1(4.55)$ \\
\hline Oblique contour of the floor & $6(21.43)$ & $9(10.59)$ & $8(12.31)$ & $3(13.6)$ \\
\hline Total & $28(100)$ & $85(100)$ & $65(100)$ & $22(100)$ \\
\hline
\end{tabular}

Table 4: Distribution of subjects on the basis gender, types of malocclusion and types of morphology $(n=200)$

\begin{tabular}{|l|c|c|c|c|c|}
\hline \multirow{2}{*}{ Morphology } & No. (\%) & \multicolumn{2}{|c|}{ Gender [No. (\%)] } & \multicolumn{2}{c|}{ Type of malocclusion [No. (\%)] } \\
\cline { 3 - 6 } & & Male & Female & I & II \\
\hline Normal sellaturcica & $79(39.5)$ & $28(41.79)$ & $51(38.35)$ & $38(38.38)$ & $41(40.59)$ \\
\hline Bridge. & $39(19.5)$ & $10(14.93)$ & $29(21.80)$ & $18(18.18)$ & $21(20.79)$ \\
\hline $\begin{array}{l}\text { Hypertrophic posterior clinoid } \\
\text { process }\end{array}$ & $8(4)$ & $3(4.48)$ & $5(3.76)$ & $5(5.05)$ & $3(2.97)$ \\
\hline $\begin{array}{l}\text { Hypotrophic posterior clinoid } \\
\text { process. }\end{array}$ & $5(2.5)$ & $4(5.97)$ & $1(0.75)$ & $1(1.01)$ & $4(3.96)$ \\
\hline $\begin{array}{l}\text { Irregularity (notching) in the } \\
\text { posterior part of the sellaturcica. }\end{array}$ & $6(3)$ & $2(2.99)$ & $4(3.01)$ & $5(5.05)$ & $1(0.99)$ \\
\hline Pyramidal shape of the dorsum sellae & $23(11.5)$ & $11(16.42)$ & $12(9.02)$ & $13(13.13)$ & $10(9.90)$ \\
\hline Double contour of the floor. & $3(1.5)$ & $1(1.49)$ & $2(1.50)$ & $1(1.01)$ & $2(1.98)$ \\
\hline Oblique anterior wall & $11(5.5)$ & $3(4.48)$ & $8(6.02)$ & $6(6.06)$ & $5(4.95)$ \\
\hline Oblique contour of the floor & $26(13)$ & $5(7.46)$ & $21(15.79)$ & $12(12.12)$ & $14(13.86)$ \\
\hline Total & $200(100)$ & $67(100)$ & $133(100)$ & $99(100)$ & $101(100)$ \\
\hline
\end{tabular}

Table 5: Distribution of subjects and comparisonof measurements of Sella turcica according to type of malocclusion $(\mathrm{n}=200)$

\begin{tabular}{|l|c|c|c|c|}
\hline Type of malocclusion & No. $(\%)$ & Length $($ Mean \pm SD) & Height (Mean \pm SD) & A-P Diameter (Mean \pm SD) \\
\hline I & $99(49.5)$ & $8.573 \pm 2.368$ & $6.323 \pm 1.608$ & $10.217 \pm 1.792$ \\
\hline II & $101(50.5)$ & $8.338 \pm 2.464$ & $6.067 \pm 1.464$ & $10.035 \pm 1.859$ \\
\hline & $200(100)$ & $0.4920^{*}$ & $0.2410^{*}$ & $0.4805^{*}$ \\
\hline
\end{tabular}

* $P$-value estimated using $t$-test for independent samples

Table 6: Distribution of subjects on the basis of gender as per groups of morphology

\begin{tabular}{|l|c|c|}
\hline \multirow{2}{*}{ Gender } & \multicolumn{2}{|c|}{ Groups of morphology [No. (\%)] } \\
\cline { 2 - 3 } & Normal & Variant \\
\hline Male & $28(35.44)$ & $39(32.23)$ \\
\hline Female & $51(64.56)$ & $82(67.77)$ \\
\hline Total & $79(100)$ & $121(100)$ \\
\hline
\end{tabular}

Table 7: Distribution of subjects on the basis of types of malocclusion as per groups of morphology

\begin{tabular}{|l|c|c|}
\hline \multirow{2}{*}{ Malocclusion } & \multicolumn{2}{|c|}{ Morphology categories [No. (\%)] } \\
\cline { 2 - 3 } & Normal & Variant \\
\hline I & $38(48.10)$ & $61(50.41)$ \\
\hline II & $41(51.90)$ & $60(49.59)$ \\
\hline Total & $79(100)$ & $121(100)$ \\
\hline
\end{tabular}

\section{Conclusion}

The finding that children with malocclusion have sellar abnormalities (either in the form of sizes or shapes) confirms a systemic aetiology of occlusal discrepancies. Assessment of the sella turcica should be carried out by orthodontist and general dental practioners during cephalometric analysis. The linear measurements (length, depth and height of sella)) can be used to measure thesize of pituitary gland and it might be of clinical importance when abnormal size of 
sella is found on lateral cehalograms. Growth of the individual can be assessed based on the size of the sella turcica at different age periods.

\section{VII . Clinical significance}

The linear dimensions of sella turcica can be used to approximate the pituitary gland size. A larger size may be an indication of pituitary tumor leading to Cushing's syndrome, amenorrhea, acromegaly. The enlarged sella turcica on a radiograph has been found to be associated with adenomas, mucocele, meningioma, primary hypothyroidism, prolactinoma, gigantism, acromegaly, empty sella syndrome, and Nelson syndrome. A small size may lead to decreased pituitary function causing symptoms such as short stature and retarded skeletal growth. Small sella turcica are notable in humans who either have an absent or a partial formed diaphragma sellae. In contrast, an abnormally small sella turcica seems to be rare and found in primary hypopituitarism and Sheehan's syndrome. Growth of the individual can be assessed based on the size of the sella turcica at different age periods.

\section{Limitations}

1. The present study was lacking in the data regarding class III subjects.

\section{References}

[1]. Shah A M, Bashir U. The Shape And Size Of The Sella Turcica In Skeletal Class I, II \& III patients, presenting at Islamic International [2]. Dental Hospital, Islamabad. Pakistan Oral \& Dental Journal.2011 JUNE,31;1

[3]. Kucia A, Jankowski T, Siewniak M, Janiszewska-Olszowska J.Sella turcica anomalies on lateral cephalometric radiographs of Polish

[4]. children. Dentomaxillofacial Radiology (2014),43:1-6

[5]. Nagraj T, Shruthi R, James L, Keerthi I, Balraj L, Goswami RD.The size and morphology of sella turcica: A lateral cephalometric [6]. $\quad$ study.Journal of Medicine, Radiology Pathology \& Surgery (2015),1:3-7

[7]. Leonardi R, Barbato E, Vichi M, Caltabiano M. A sella turcica bridge in subjects with dental anomalies. Eur J Orthod 2006;28:580-5.

[8]. Abdullah I M, Mohammed L K.Normal and Abnormal Variations of Sella Turcica in Three Facial Types of Adolescent Iraqi

[9]. Samples.Medical Journal of Babylon,2015,12;3: 653-660.

[10]. Anwar N and Fida M. Evaluation of dentoalveolar compensation in skeletal class II malocclusion in a Pakistan University Hospital [11]. settingJournal of the College of Physicians and Surgeons Pakistan, 19(1), 11-6.

[12]. Axelsson S, Storhaug K, Kjaer I. Post-natal size and morphology of the sella turcica in Williams syndrome. Eur J Orthod 2004;26:613[13]. 21.

[14]. Alkofide EA. The shape and size of the sella turcica in skeletal Class I, Class II, and Class III Saudi subjects. Eur J Orthod 2007;29:457[15]. 63.

[16]. Jones RM, Faqir A,Millett DT,Moos KF,McHugh S. Bridging and dimensions of sella turcica in subjects treated by surgical-orthodontic [17]. means or orthodontics only. Angle Orthod 2005; 75: 714-18.

[18]. Becktor JP, Einersen S, Kjaer I. A sella turcica bridge in subjects with severe craniofacial deviations. Eur J Orthod 2000; 22 : 69-74.

[19]. Marsan G, O “ ztas, E. Incidence of bridging and dimensions of sella turcica in Class I and Class III Turkish adult female patients. World J

[20]. Orthod 2009; 2: 99-103.

[21]. Sathyanarayana HP, Kailasam V, Chitharanjan AB. Sella turcica - its importance in orthodontics and craniofacial morphology. Dent Res J

[22]. 2013; 10: 571-5

[23]. Tetradis S, Kantor ML. Prevalence of skeletal and dental anomalies and normal variants seen in cephalometric and other radiographs of

[24]. orthodontic patients. Am J Ortho Dentofacial Orthop 1999;116:572-77.

[25]. Gordon M B, Bell AL. A roentgenographic study of the sella turcica in normal children. New York State Journal of Medicine 1922;22:5459.

[26]. Camp JD. The Normal and pathological anatomy of the sella turcica as revealed by roentgenograms. American journal of Roentgenology

[27]. 1924;12:143-56.

[28]. Kantor ML, Norton LA. Normal radiographic anatomy and common anomalies seen in cephalometric films. American journal of Orthodontics and Dentofacial Orthopedics 1987;91:414-26.

[29]. Davidoff LM, Epstein BS. The abnormal pneumoencephalogram. Philadelphia: Lea and Febiger; 195

[30]. [18] Kier EL. "J" and "omega" shape of sella turcica. Anatomic clarification of radiologic misconceptions. Acta Radiol Diagn (Stockh) 1969;9:91- 94 .

[31]. Quakinine G E, Hardy J. Microsurgical anatomay of the pituitary gland and the pituitary gland and the sellar region: the pituitary Gland The American surgeon 1987;53:285-90.

[32]. Asad S, Hamid W. Assessment and comparison of dimensions of Sella turcica in skeletal class I \& skeletal class II cases. Pak Oral Dental J 2005;25:59-64.

[33]. srael H. Continuing growth in sella turcica with age. Am J Roentgenol Radium Ther Nucl Med 1970;108:516-27.

[34]. [22] Silverman FN. Roentgen standards fo-size of the pituitary fossa from infancy through adolescence. Am J Roentgenol Radium Ther Nucl Med 1957;78:451-60.

[35]. Haas LL. The size of the sella turcica by age and sex. Am J Roentgenol Radium Ther Nucl Med 1954;72:754-61.

[36]. Preston CB. Pituitary fossa size and facial type. Am J Orthod 1979;75:259-63.

[37]. Friedland B, Meazzini C. Incidental finding of an enlarged sella turcica on a lateral cephalogram. Am J Orthod Dentofac Orthop

[38]. 1996;110(5):508-512

[39]. Tassoker M, Ozcan S.Clinical And Radiological Significance of Sella Turcica: A Literature Review. IOSR Journal of Dental and Medical

[40]. Sciences (IOSR-JDMS).August 2016,Volume15; Issue8:PP108-113

[41]. Kier E L 1969 ' J' and 'omega' shape of sella turcica: anatomic clarifi cation of radiologic misconceptions . Acta Radiologica: Diagnosis 9: $91-94$ 